\title{
UNSTEADY FLOW PHENOMENA IN TURBINE RIM SEALS
}

\author{
Paul F Beard \\ Osney Thermofluids Laboratory \\ Dept. of Engineering Science \\ University of Oxford \\ Oxford, OX2 0ES. UK \\ paul.beard@eng.ox.ac.uk
}

\author{
John Chew \& Feng Gao \\ Faculty of Engineering \& \\ Physical Sciences \\ University of Surrey \\ Guildford, GU2 7XH. UK \\ j.chew@surrey.ac.uk \\ f.gao@surrey.ac.uk
}

\author{
Kam S Chana \\ Osney Thermofluids Laboratory \\ Dept. of Engineering Science \\ University of Oxford \\ Oxford, OX2 OES. UK \\ kam.chana@eng.ox.ac.uk
}

\begin{abstract}
While turbine rim sealing flows are an important aspect of turbomachinery design, affecting turbine aerodynamic performance and turbine disc temperatures, the present understanding and predictive capability for such flows is limited. The aim of the present study is to clarify the flow physics involved in rim sealing flows and to provide high quality experimental data for use in evaluation of CFD models. The seal considered is similar to a chute seal previously investigated by other workers, and the study focuses on the inherent unsteadiness of rim seal flows, rather than unsteadiness imposed by the rotating blades. Unsteady pressure measurements from radially and circumferentially distributed transducers are presented for flow in a rotor-stator disc cavity and the rim seal without imposed external flow. The test matrix covered ranges in rotational Reynolds number, $\mathrm{Re}_{\phi}$, and non-dimensional flow rate, $\boldsymbol{C}_{\boldsymbol{w}}$, of $2.2-3.0 \times 10^{6}$ and $0-3.5 \times 10^{3}$ respectively. Distinct frequencies are identified in the cavity flow and detailed analysis of the pressure data associates these with large scale flow structures rotating about the axis. This confirms the occurrence of such structures as predicted in previously published CFD studies and provides new data for detailed assessment of CFD models.
\end{abstract}

$\begin{array}{ll}\text { NOMENCLATURE } \\ b & \text { disc radius, m } \\ C_{w} & \text { non-dimensional flow rate }=\dot{m} / \mu b \\ f & \text { angular frequency } \\ \text { FFT } & \text { Fast Fourier Transform } \\ \dot{m} & \text { cavity mass flow rate } \\ n & \text { arbitrary integer } \\ N & \text { number of circumferential lobes of flow structure } \\ \text { ORF } & \text { Oxford Rotor Facility } \\ p & \text { static pressure } \\ p_{p e a k} & \text { amplitude of unsteady pressure at peak in frequency } \\ \operatorname{Re}_{\varnothing} & \text { (FFT) spectra } \\ & \text { rotational Reynolds number }=\rho \Omega b^{2} / \mu\end{array}$

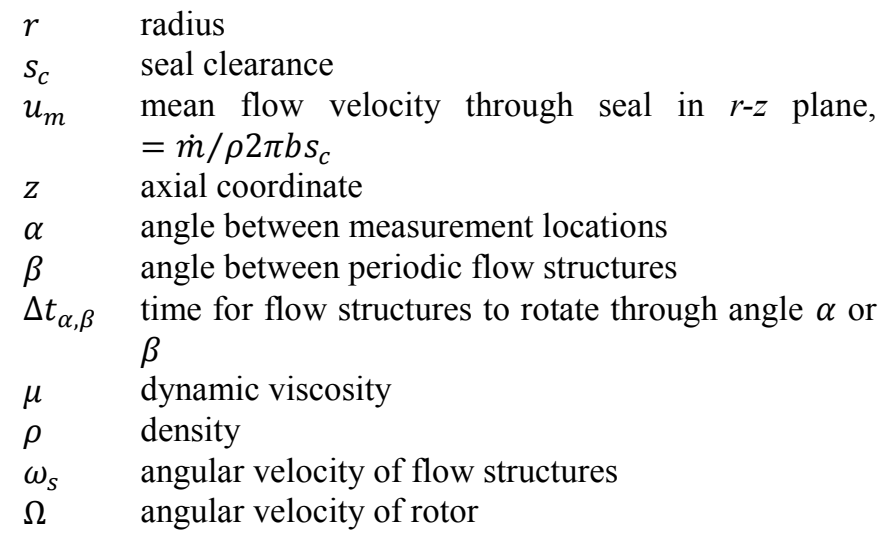

Subscripts

ext external to cavity

1 to 10 pressure measurement location

\section{INTRODUCTION}

Turbine rim sealing flows are an important aspect of turbomachinery design, affecting both turbine aerodynamic performance and turbine disc temperatures. Seal clearances must accommodate relative movements between rotating and stationary components during engine operation and this can require use of additional cooling air to prevent ingestion of the hot main annulus gas into the turbine disc cavity. In addition, the rim seal design may affect the aerodynamic losses associated with interaction of the cooling air and the main turbine gas flow. Modelling of such flows with computational fluid dynamics (CFD) has proved difficult and several studies have indicated that the rim seal gap and disc cavity flows can contain large scale unsteady flow structures with frequencies unrelated to those associated with the rotating blades. The aim of the present study is to clarify the flow physics involved through experimental investigation and to provide high quality experimental data for use in evaluation of CFD models.

Even without circumferential pressure and flow variations caused by the stationary vanes and rotating blades in the main 
gas path, the pumping effect of the rotating disc tends to draw flow into a rotor stator disc cavity which has an opening to the atmosphere at the outer radius. Flow in the cavity is drawn towards the disc and then spirals radially outwards in a thin boundary layer due to centrifugal force. In a closed rotor/stator disc cavity the pumped flow will recirculate, flowing radially inwards in the boundary layer on the stationary disc. With a gap between the rotor and stator at the outer radius, some or all of the flow in the disc boundary layer will leave the cavity and will be replaced by fluid drawn in through the gap from the surrounding environment. As reported by Chew et al. [1] and Boudet et al. [2], a 3D unsteady Reynolds-averaged Navier-Stokes (RANS) CFD model gave good agreement with an empirical correlation for sealing effectiveness in a rotor/stator disc cavity with a simple axial clearance seal at the periphery. The CFD solution was inherently unsteady and 3D, despite the geometry being axisymmetric and the boundary conditions being steady and axisymmetric. The sealing effectiveness was determined in both the CFD and the associated experimental correlation from gas concentration measurements. There was no direct experimental confirmation of the unsteady flow phenomena predicted by the CFD.

Further agreement between unsteady RANS models and experiment has been demonstrated by Cao et al. [3]. This study considered a turbine in which the rim gap consisted of a simple axial gap between the rotating disc and stationary diaphragm. The RANS models included the disc cavity and main annulus flow but did not include the vanes and blades present in the experiment. Again the CFD solutions were found to be inherently 3D and unsteady. Reasonable agreement between CFD and measurements of pressure levels in the cavity and pressure fluctuations recorded from a single fast response transducer on the stator diaphragm in the outer part of the rim gap was demonstrated.

Comparisons between CFD and measurements of sealing effectiveness for a chute seal, in which the stator overlaps the rotor axially, have been less encouraging than for axial clearances. The rim seal gap in the chute seal is bounded by an inner conical rotor surface and an outer conical stator surface. Boudet et al. [2],[4] compared RANS CFD solutions with measurements by Gentilhomme et al. [5] of sealing effectiveness and mean pressure from a turbine rig. CFD solutions including both blades and vanes were obtained. Unsteady flow frequencies were identified with unsteadiness around $44 \%$ of blade passing frequency associated with effects within the rim seal and possible Taylor-Couette instability. While the CFD was shown to predict some experimentally observed trends correctly, the degree of ingestion predicted was generally below that obtained experimentally. O'Mahoney et al. [6],[7] extended the CFD studies of this turbine to large eddy simulation (LES). Results showed significant improvement in comparisons with measurements. Large scale unsteadiness in the LES was less coherent than in RANS solutions with unsteadiness observed over a range of frequencies rather than at a distinct mode. In the first of these two papers it was also reported that extending the
RANS model by Boudet et al. to a full $360^{\circ}$ sector did not notably affect the solution.

In addition to the series of investigations described above, other workers have reported similar unsteady effects. Comparisons between experiment and CFD have been reported by Jakoby et al. [8], Zhou et al. [9] and Wang et al. [10]. Jakoby et al. found large scale unsteady flow features in a turbine disc cavity with an axial seal in their RANS solution, and reported that use of a full $360^{\circ}$ sector model gave improved predictions of ingestion compared to small sector models. Their results were also supported by pressure measurements showing low frequency unsteadiness unrelated to blade passing frequency. Zhou et al. found that their small sector unsteady RANS analysis under-predicted ingestion in their turbine disc cavity with a radial clearance seal. This analysis was extended to full $360^{\circ}$ turbine stage calculations by Wang et al. These solutions showed large scale unsteady flow features associated with rim seal ingestion and unrelated to the blade passing frequency. Sealing effectiveness was considerably lower than for the small sector solutions, and closer to experimental results with the $360^{\circ} \mathrm{CFD}$ solution showing more ingestion than measured. No comparison was made with unsteady pressure measurements, although an earlier build of the rig, reported by Roy et al. [11], had shown experimental evidence of pressure fluctuations at a frequency below that of the blade passing. The authors suggested these may correspond to the unsteady flow in the rim gap detected by Cao et al.

Further relevant research has considered the physical flow mechanisms involved in the ejection of the rim seal flow into the turbine main flow path. Schuepbach et al. [12] identified unsteady flow in the hub region of the main gas path at about half blade passing frequency and noted that this was possibly associated with cavity modes. Rabs et al. [13] deduced from CFD that Kelvin-Helmholtz type vortices developed in the shear layer between the seal purge flow and the main flow. These were suppressed by flow interactions associated with the guide vanes and blades, especially at low rim seal flow rates. The CFD severely underpredicted ingestion at low flow rates and this was attributed to the inability of the relatively small sector CFD domain to capture large scale unsteadiness. The detailed CFD investigation reported by Chilla et al.[14] also identifies natural unsteadiness associated with the shear layer between the seal flow and main annulus flow. The frequency of the unsteadiness was affected by the rim seal design and was suppressed by increasing the seal flow rate or reducing the velocity difference between the two streams.

While it is clear that considerable progress has been made in understanding rim seal flows, it is also clear that the flow physics is complex and not yet fully understood. There is limited time resolved experimental data available and comparison between different datasets is complicated by the wide range of different geometries and operating conditions studied, and measurement uncertainties. CFD studies have undoubtedly given insight into flow physics and direction to some experiments but are subject to considerable uncertainties. These include turbulence modeling, assumptions of circumferential periodicity, numerical 
errors, and limited simulation times. With their inherent limitations, RANS turbulence models cannot be assumed to be correct. Chilla et al. suggested that further insight into flow mechanisms might be gained from study of canonical cases such as flow over a trench or the mixing of two flows with different velocities.

In this paper a relatively simple rotating flow configuration, related to earlier experimental and numerical research by Boudet et al. [2], Gentilhomme et al. [5] and O'Mahoney et al. [6], is investigated experimentally. Focusing on the inherent unsteadiness of rim seal flows, rather than unsteadiness imposed by rotating blades, the experiments consider a rotor/stator disc cavity without external flow.

\section{EXPERIMENTAL FACILITY}

Historically, the Oxford Rotor Facility (ORF), described by Ainsworth et al., [15] has been used for experimental investigations of the steady and unsteady aero-thermal behaviour of high pressure transonic turbine stages. It is a transient test facility that uses an isentropic light piston tube to supply the working (mainstream) air supply. A schematic of the facility is shown in Figure 1 below.

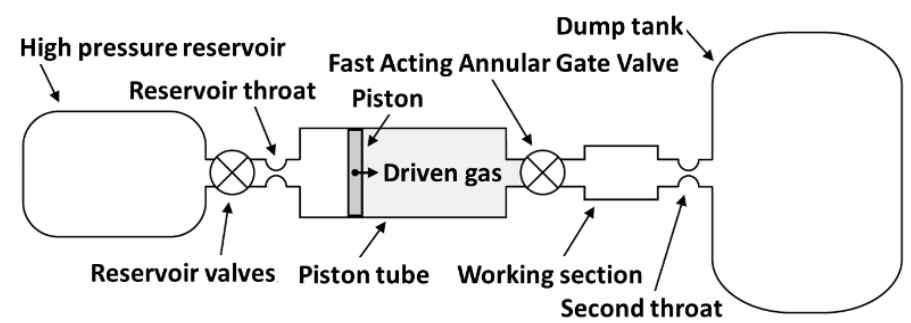

Figure 1: Schematic of the Oxford Rotor Facility

This study focused on the inherent unsteadiness of rim seal flows, rather than unsteadiness imposed by the rotating blades, and therefore the facility was operated without mainstream air and with a clean annulus (without blading) at atmospheric pressure. The sectional drawing of the working section during these experiments is shown in Figure 2(a). For all experiments, the turbine vanes and rotors blades were removed and replaced by (dummy) vane and rotor platform rings, numbered ' 4 ' and ' 5 ' respectively. These components also formed the upstream (static) and downstream (rotating) geometry for the rim seal and cavity walls beneath the seal. The design matched the chute seal design studied by Gentilhomme et al. [5] and is shown in Figure 2(b). The nominal seal clearance was $1 \mathrm{~mm}$ with a rotor speed of $9000 \mathrm{rpm}$. The rotor disc spins anti-clockwise when viewed from downstream. During the design process, FEA was used to predict the radial growth of the rotor disc, and was later measured using a laser micrometer. The nominal axial seal overlap was $2 \mathrm{~mm}$ and the width of the rim seal feed cavity was kept at $10 \mathrm{~mm}$ as far inboard as possible. All of the rim seal and cavity walls were smooth. As for the geometry studied by Gentilhomme et al., sealing air entered the rim seal cavity through an inboard overlapping seal, with $1 \mathrm{~mm}$ clearance and $3 \mathrm{~mm}$ overlap.

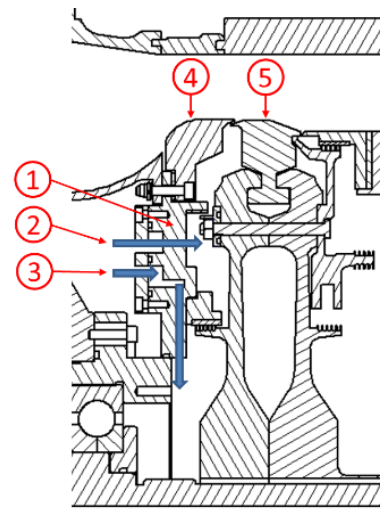

(a)

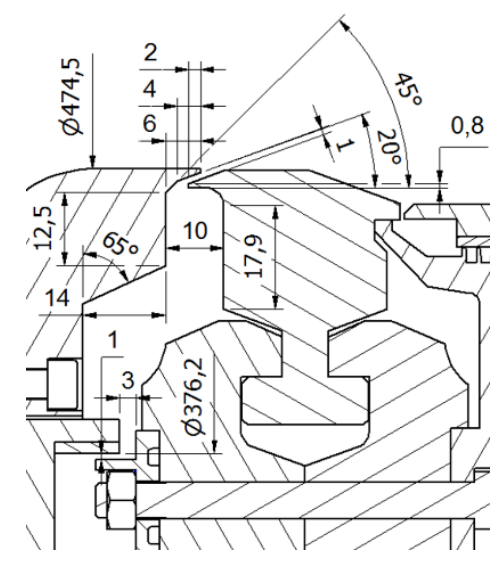

(b)
Figure 2: (a) Drawing of ORF working section, (b) Rim seal geometry (dimensions in $\mathrm{mm}$ ).

Sealing air was delivered to outer and inner front rotor cavities (separated by a labyrinth seal) through the feed distribution ring, numbered ' 1 ' in Figure 2(a). The distribution ring is a complete ring with outer and inner annular feed cavities from which 'primary' and 'labyrinth balancing' air was injected into the front rotor cavities. The primary rim seal air feed, numbered ' 2 ', enters the outer cavity in the feed distributor through six evenly distributed $9 \mathrm{~mm}$ diameter inlet feed holes and exits into the front rotor cavity between the (inner) labyrinth seal and (outer) overlapping seal through 24 evenly distributed $3 \mathrm{~mm}$ diameter holes. A second air feed into the inner front rotor cavity, numbered ' 3 ', was included to ensure the pressure was balanced across the inner labyrinth seal. This mitigated against small leakages through the bearing seals or along the shaft. In practice, the balancing mass flow was at least an order of magnitude inner than the primary feed mass flow showing the inner front rotor cavity was well sealed.

The primary rim seal air feed was fed from a 100 psi supply, passed through a 20 micron filter and the mass flow was set by an Alicat MCR Series 10-2000 SLPM Precision Gas Mass Flow Controller before entering the feed distribution ring. The required mass flow rate was set locally prior to a test, and

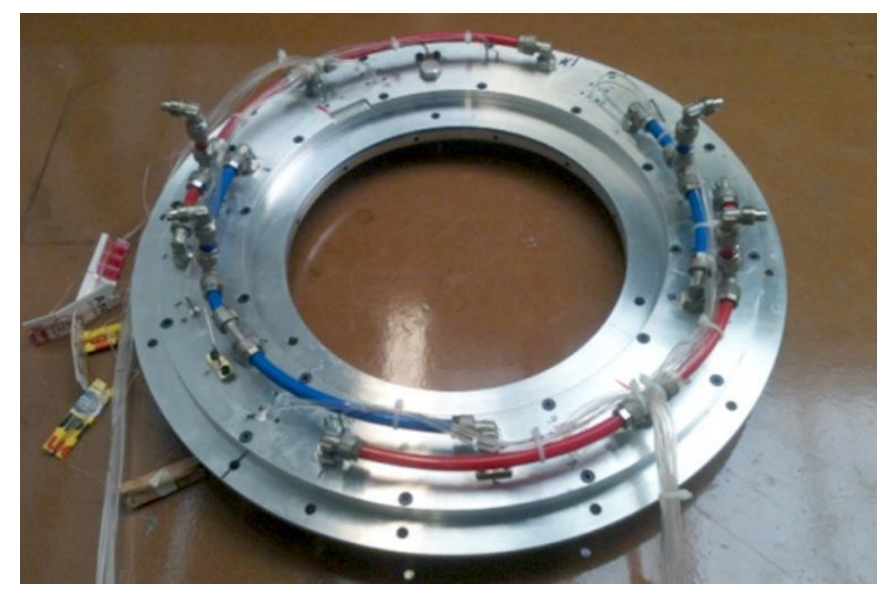

Figure 3: Feed distributor with instrumentation. 
recorded using the $0-10 \mathrm{~V}$ proportional output signal from the controller during the experiment. The quoted accuracy for the mass flow controller was $\pm 0.8 \%$ of reading plus $\pm 0.2 \%$ of full scale (equal to $\pm 0.08 \mathrm{~g} / \mathrm{s}$ ). The air supply for balancing the pressure across the inner labyrinth seal was simply controlled using a $0-15$ psi regulator. Both air supplies were delivered to the facility through $15 \mathrm{~mm}$ diameter plastic piping, split into two $9 \mathrm{~mm}$ diameter pipes and connected to the feed distributor within the facility. A photograph of the fully instrumented feed distributor with the connecting feed pipework attached is shown in Figure 3. The red and blue tubes supply the primary rim seal air and secondary balancing air respectively.

\section{HIGH BANDWIDTH INSTRUMENTATION}

Unsteady pressure measurements were taken at 10 locations using Kulite ${ }^{\mathrm{TM}}$ XCS-062-20psiA pressure sensors. These are high sensitivity ultra-miniature versions of the standard XCQ type sensor. These piezo-resistive (silicon-on-insulator) pressure sensors have a diameter of $1.7 \mathrm{~mm}$, a shortened length of $9.5 \mathrm{~mm}$, a typical natural frequency of $200 \mathrm{kHz}$ and are temperature compensated up to $80^{\circ} \mathrm{C}$. The unsteady pressure sensors were mounted in small instrumentation blocks that were positioned strategically around the vane platform ring (item ' 4 ' in Figure 2(a)). The instrumentation blocks were machined in conjunction with the vane platform ring to ensure there were no surface discontinuities. Sensors were positioned radially and circumferentially around the rim seal as shown in Figure 4 and summarised in Table 1 below. In Table 1, angles are given in a clockwise direction from top-dead-center viewing from downstream. Five sensors were positioned radially, with two sensors mounted on the angled faces of the rim seal. A photograph of these radially orientated sensors is shown in Figure 5 below. An additional five sensors were spaced circumferentially around the rim seal feed cavity at constant radius (equal to radial position 1002). The circumferential sensor positioning provided combinations of sensor spacing every $5^{\circ}$ between $5^{\circ}$ to $30^{\circ}$, and every $10^{\circ}$ between $30^{\circ}$ to $90^{\circ}$.

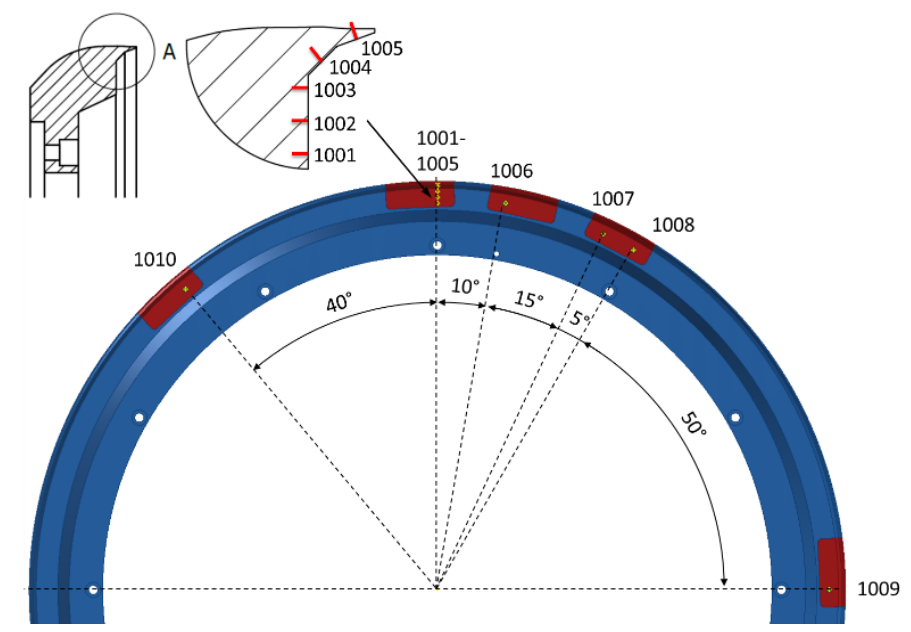

Figure 4: Schematic of unsteady pressure sensors instrumentation on vane platform ring (viewed from downstream)

\begin{tabular}{|c|c|c|c|c|c|}
\hline Sensor & Radius & Angle \\
\hline \hline 1001 & $224 \mathrm{~mm}$ & $0^{\circ}$ \\
\hline 1002 & $227.5 \mathrm{~mm}$ & $0^{\circ}$ \\
\hline 1003 & $231 \mathrm{~mm}$ & $0^{\circ}$ \\
\hline 1004 & $234.1 \mathrm{~mm}$ & $0^{\circ}$ \\
\hline 1005 & $235.9 \mathrm{~mm}$ & $0^{\circ}$ \\
\hline 1006 & $227.5 \mathrm{~mm}$ & $10^{\circ}$ \\
\hline 1007 & $227.5 \mathrm{~mm}$ & $25^{\circ}$ \\
\hline 1008 & $227.5 \mathrm{~mm}$ & $30^{\circ}$ \\
\hline 1009 & $227.5 \mathrm{~mm}$ & $90^{\circ}$ \\
\hline 1010 & $227.5 \mathrm{~mm}$ & $-40^{\circ}$ \\
\hline
\end{tabular}

Table 1: Summary of high bandwidth sensor locations

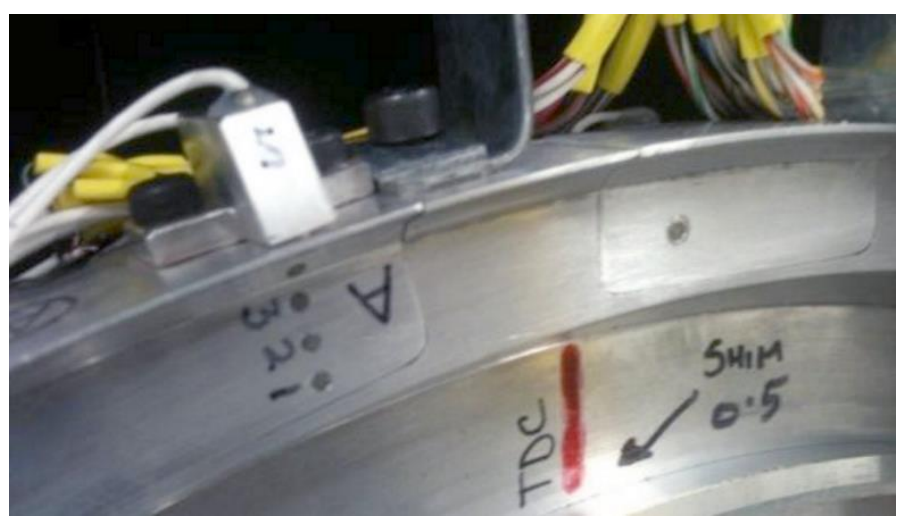

Figure 5: Unsteady pressure sensors mounted in vane platform ring

The output from the Kulite ${ }^{\mathrm{TM}}$ sensors is ratiometric and of order $200 \mathrm{mV}$ at full-scale (with a nominal $10 \mathrm{~V}$ excitation). The transducer output signal was amplified and conditioned using bespoke (HTA3) electronics developed at Oxford University. AC coupling was used as the primary interest was the unsteady pressure signal and a gain of 100 was chosen to achieve a voltage level output signal. Each channel also included an anti-aliasing filter with a cut-off frequency of $412 \mathrm{kHz}$, less than half the sampling frequency of $1 \mathrm{MHz}$, and individually calibrated up to $1 \mathrm{MHz}$. The amplifiers also provided a smooth $12 \mathrm{~V}$ excitation voltage to the Kulite pressure transducers.

Allowing for uncertainties in the pressure sensor nonlinearity, hysteresis and repeatability $( \pm 0.1 \%)$, the gain calibration of the HTA3 amplifiers $( \pm 0.1 \%)$, the measured sensor excitation voltage $( \pm 0.005 \%)$, and sensor sensitivity shift due to thermal effects $( \pm 0.05 \%)$, the overall uncertainty in the unsteady pressure measurements was estimated at $\pm 0.15 \%$. As the sensor outputs were AC coupled, zero drift was removed.

\section{LOW BANDWIDTH INSTRUMENTATION}

Steady pressure and temperature measurements were acquired throughout the feed system, feed cavities and rim seal. Steady pressure measurements in the rim seal and across the (outer) overlapping seal and (inner) labyrinth seal were acquired using Sensor Technics BTEM Series 0-70mbar pneumatic differential pressure transducers with a nominal error band of $\pm 0.2 \%$ of full-scale output. The measurements in the region of the rim seal were arranged in five radial locations matching the radial positions of the radially spaced unsteady sensors (see Figure 4). All differential pressure measurements were referenced to the mainstream pressure (atmospheric). 
Absolute pressure measurements were also conducted at a number of positions in the air system; the outer and inner feed distributor cavities ( 3 evenly spaced locations in each), $14 \mathrm{~mm}$ inboard of the (outer) overlapping seal in the outer rotor front cavity ( $r=176 \mathrm{~mm}$ at 4 evenly spaced locations), and $19 \mathrm{~mm}$ outbound of the (inner) labyrinth seal in the outer rotor front cavity ( $r=151.5 \mathrm{~mm}$ at 4 evenly spaced locations). All absolute pressure measurements were conducted using Sensor Technics Series CTE8000 0-2 bar absolute pressure transducers with a typical error band of $\pm 0.1 \%$ of the full-scale output. All tappings were $1 \mathrm{~mm}$ diameter holes, countersunk to connect with $1.6 \mathrm{~mm}$ diameter bulged stainless steel tubulations, which were connected to the transducers using $\emptyset 1.6 \mathrm{~mm}$ vinyl tubing.

All gas temperature measurements were conducted using ktype $\left(\varnothing 3 \times 10^{-3}\right.$ in) bare bead thermocouples. Measurements were taken $14 \mathrm{~mm}$ inboard of the (outer) overlapping seal in the outer rotor front cavity ( $r=176 \mathrm{~mm}$ at 6 evenly spaced locations), and in the outer and inner feed distributor cavities ( 3 evenly spaced locations in each).

\section{EXPERIMENTAL TEST MATRIX}

Experiments were conducted at two rim seal gaps: $1 \mathrm{~mm}$ (nominal) and $1.65 \mathrm{~mm}$ over a range of rotational speeds (7000 to $9000 \mathrm{rpm}$ ) and seal mass flows (0 to $19.5 \mathrm{~g} / \mathrm{s})$. These test conditions correspond to ranges in rotational Reynolds number, $\mathrm{Re}_{\varnothing}$, and non-dimensional flow rate, $C_{w}$, of $2.2-3.0 \times 10^{6}$ and $0-3.5 \times 10^{3}$ respectively. The axial overlap of the rim seal was 2 $\mathrm{mm}$ and $0.2 \mathrm{~mm}$ respectively for the two gap sizes. Table 2 below summarises the test matrix.

\begin{tabular}{|c|c|c|c|c|c|c|c|c|c|c|}
\hline \multirow{2}{*}{$\begin{array}{c}\text { Rotational } \\
\text { Speed }\end{array}$} & \multicolumn{10}{|c|}{ Rim seal mass flow rate, g/s } \\
\cline { 2 - 13 } & 0 & 1.5 & 3.5 & 5.5 & 7.5 & 9.5 & 11.5 & 13.5 & 15.5 & 19.5 \\
\hline $7000 \mathrm{rpm}$ & $\bullet$ & $\mathrm{o}$ & $\bullet$ & $\mathrm{o}$ & $\bullet$ & $\mathrm{o}$ & $\bullet$ & $\mathrm{o}$ & $\bullet$ & $\mathrm{X}$ \\
\hline $8000 \mathrm{rpm}$ & $\bullet$ & $\mathrm{o}$ & $\bullet$ & $\mathrm{o}$ & $\bullet$ & $\mathrm{o}$ & $\bullet$ & $\mathrm{o}$ & $\bullet$ & $\mathrm{X}$ \\
\hline $9000 \mathrm{rpm}$ & $\bullet$ & $\mathrm{o}$ & $\bullet$ & $\mathrm{o}$ & $\bullet$ & $\mathrm{o}$ & $\bullet$ & $\mathrm{o}$ & $\bullet$ & $\mathrm{X}$ \\
\hline
\end{tabular}

Table 2: Experimental test matrix (symbols ' $\bullet$ ', 'o' \& 'x' identify tests with: both seal gaps, $1 \mathrm{~mm}$ gap and $1.65 \mathrm{~mm}$ gap respectively)

\section{INSTALLATION AND COMMISSIONING}

To adjust the concentricity of the vane platform ring to ensure an even rim seal gap around the annulus, the assembly of the working section allowed this component to float by $2 \mathrm{~mm}$ with respect to the machine axis. Initially, the vane platform ring was assembled centrally with respect to the feed distributor. Subsequently, the rotor disc was fitted and the static rim seal gap was surveyed around the annulus using feeler gauges to an accuracy of $\pm 0.02 \mathrm{~mm}$. The rotor disc was then removed and the positioning of the NGV hub platform ring appropriately adjusted. This sequence was repeated until the mean eccentricity was minimised.

After balancing the rotor assembly, a laser micrometer was mounted on the turbine casing to measure the radial growth of the rotating assembly up to $9000 \mathrm{rpm}$. Figure 6 shows the results from two spin-ups. The measured mean radial growths at 7000 , 8000 and $9000 \mathrm{rpm}$ were $0.069,0.098$ and $0.132 \mathrm{~mm}$

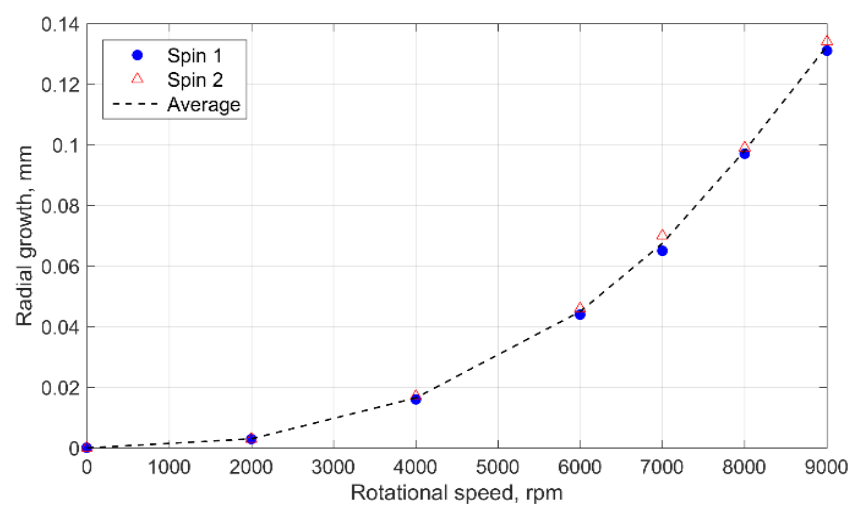

Figure 6: Radial growth of rotor assembly against rotational speed.

respectively. With a $20^{\circ}$ chute seal, this corresponded to reductions in seal gap of $0.064,0.092$ and $0.124 \mathrm{~mm}$ respectively. To achieve the desired seal gap (1 $\mathrm{mm}$ or $1.65 \mathrm{~mm})$ at the nominal speed of $9000 \mathrm{rpm}$, the static gap was set $0.12 \mathrm{~mm}$ larger than this.

During installation, the static seal gap was measured every $45^{\circ}$. The mean, maximum, minimum and standard deviation of the measured deviations from the desired static seal gap were $-0.005 \mathrm{~mm},+0.08 \mathrm{~mm},-0.06 \mathrm{~mm}$ and $0.06 \mathrm{~mm}$, respectively. Allowing for uncertainty in measuring the static seal gap with feeler gauges $( \pm 0.01 \mathrm{~mm})$ and the uncertainty in the rotor radial growth measurement $( \pm 0.02 \mathrm{~mm})$, the uncertainty in mean seal gap was estimated at $\pm 0.03 \mathrm{~mm}$, or $\pm 3 \%$ and $\pm 0.18 \%$ for the $1 \mathrm{~mm}$ and $1.65 \mathrm{~mm}$ seal gaps respectively. The mean and maximum deviations in seal gap corresponded to $-0.5 \%$ and $+8 \%$ for the $1 \mathrm{~mm}$ seal respectively, and $-0.3 \%$ and $+4.8 \%$ for the $1.65 \mathrm{~mm}$ seal gap respectively. These uncertainties are small compared to the change in seal gap of $65 \%$ considered in this paper.

\section{MEAN FLOW RESULTS}

While the main objective of the study was to obtain fast response unsteady data, the results for the mean flow, as represented by the static pressure measurements at tappings 1 to 5 (corresponding to sensor positions 1001 to 1005 in Figure 4 respectively) and the external (or atmospheric) pressure are also of interest. As the maximum pressure differences in the experiments were less than $1 \%$ of atmospheric pressure and the temperature variations were similarly small, fluid density and viscosity are assumed constant for each experiment and values were calculated from the external (atmospheric) pressure and coolant supply temperature measured inboard of the (outer) overlapping seal in the outer rotor front cavity. The cavity flow is expected to be dominated by rotation so pressures are nondimensionalised using the dynamic head at disc rim speed.

Figure 7 shows results for the two seal clearances at the three test speeds, with no net supply flow. Here tapping 1 at $r / b=$ 0.946 is taken as a reference pressure with measurements at the other tappings plotted against radial position. The external pressure is plotted at $r / b=1.01$, and a forced vortex pressure distribution at $55 \%$ of disc speed is also plotted. It is clear that 


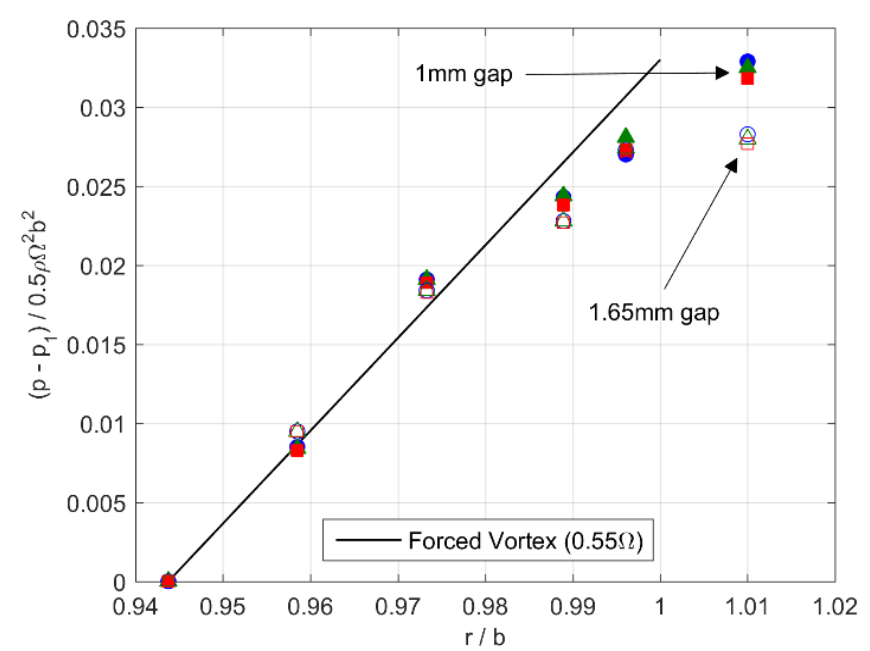

Figure 7: Radial data of mean pressure relative to tapping 1 for all tests with $C_{w}=0$. Results at $r / b=1.01$ represent external (atm) pressure.

the cavity pressure distribution is close to the forced vortex for all 6 tests. This indicates insensitivity of the cavity flow to the expected ingestion of external flow which will depend on the seal clearance. The external pressure results show significant differences between the two seal clearances, but are insensitive to rotor speed. This shows that, as expected, the clearance affects the pressure difference across the seal.

Figure 8 shows pressure at tapping 4 relative to the external pressure. By plotting all the test results against the mean seal velocity $\left(u_{m}=\dot{m} / \rho 2 \pi b s_{c}\right)$ divided by the disc speed, the data collapses approximately onto two straight lines corresponding to the two clearances.

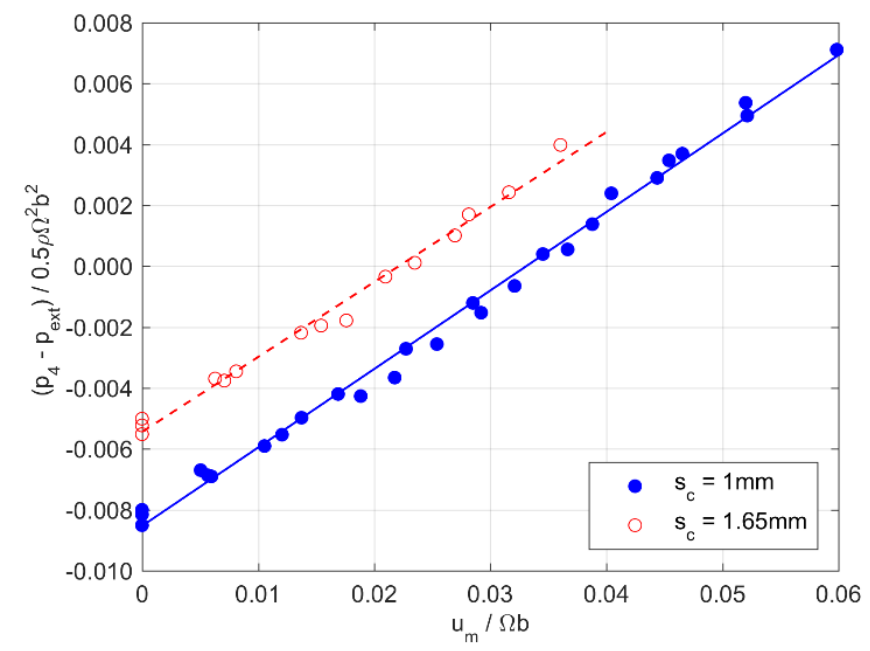

Figure 8: Variation of mean pressure at tapping $4(r / b=0.988)$ relative to external tapping with cavity flow rate for the two seal gaps.

The point of zero pressure difference across the seal has been used in some studies to indicate the flow rate required to prevent ingestion into the cavity. The pressure at tapping 4 equals the external pressure when $u_{m} \sim 0.033$ and 0.022 for the $1 \mathrm{~mm}$ and $1.65 \mathrm{~mm}$ seal clearances respectively. These values are lower than those estimated previously for simple radial and axial clearance seals. For reference, the correlation of Bayley and Owen [16] of minimum sealing flow rate for a simple axial clearance seal gives $u_{m} / \Omega b \sim 0.097$, and for a simple radial seal (for which there is more uncertainty than the axial seal) analysis by Chew [17] indicated $u_{m} / \Omega b \sim 0.052$. While the chute seal tested in this study may perform better than the simple seals, it should be noted that use of tapping 3 (at $r / b=0.975$ ) rather than tapping 4 would indicate zero pressure difference across the seal at the higher values of $u_{m} / \Omega b$ of 0.05 and 0.04 for the two seal clearances.

\section{UNSTEADY PRESSURE RESULTS}

\section{Data Processing}

The unsteady (ac coupled) voltage signal from each fast response sensor was converted to pressure with knowledge of the frequency response of the HTA3 amplifier channel and calibration data provided by the manufacturer.

The blue lines in Figure 9 show typical processed unsteady pressure data at $9000 \mathrm{rpm}$ from radial tapping 1001 (see Figure 4) as: top plot - typical data for one revolution, middle plot - ensemble average of data over 150 rotor revolutions, bottom plot - mean frequency spectra for 150 rotor revolutions. It is clear from the frequency spectra that frequencies relating to 30 and 60 times the disc speed were present, and this was true for all data acquired. The frequency relating to $f / \Omega=30$ is also clearly present in the ensemble averaged raw data. It is believed that these signal frequencies were created by the 30
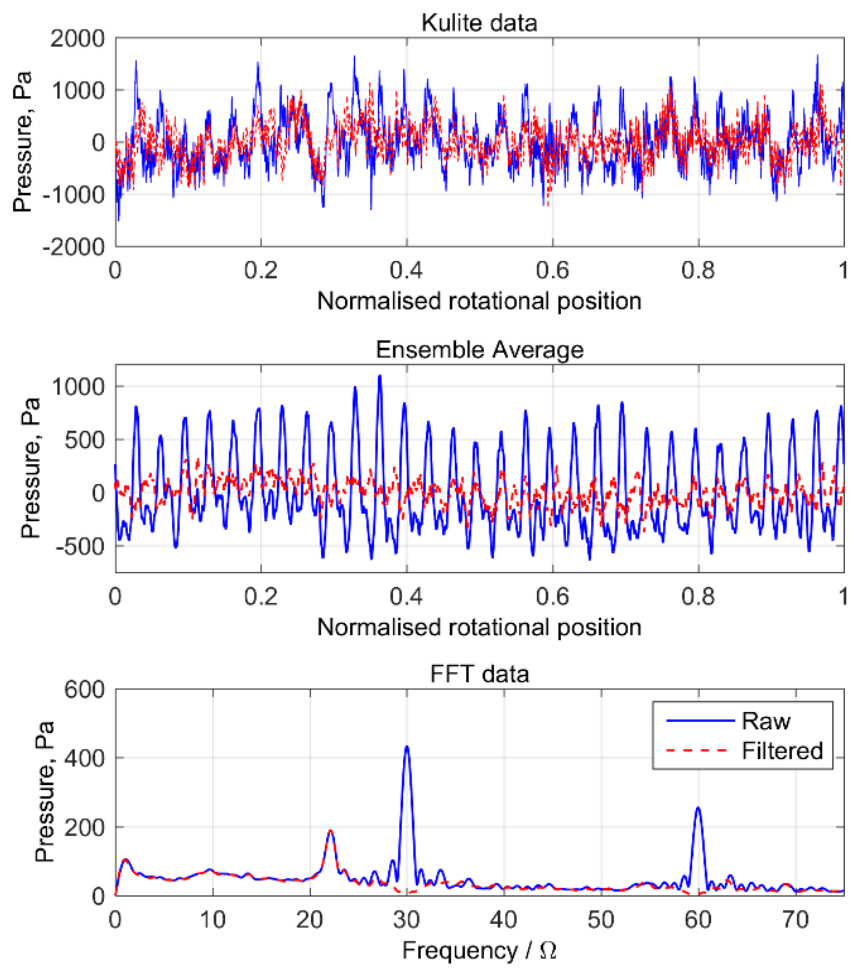

Figure 9: Comparison of raw and filtered unsteady pressure data at position 1001: top - raw data, middle - ensemble average for 150 revs, bottom - frequency spectra. $\Omega=9000 \mathrm{rpm} . s_{c}=1 \mathrm{~mm}, \dot{m}=3.55 \mathrm{~g} / \mathrm{s}$ $\left(\operatorname{Re}_{\emptyset}=2.8 \times 10^{6}, C_{w}=740\right)$ 
disc bolts rotating inboard of the overlapping seal feeding the rim cavity. Consequently, the raw data was filtered by a Butterworth impulse band-stop filtering using the Matlab signal processing toolbox. Filters were designed with $-3 \mathrm{~dB}$ cut-off frequencies at $\pm 250 \mathrm{~Hz}$ from $f / \Omega=30$ and 60 for each test rotational speed. The red lines show filtered versions of the raw data and corresponding frequency spectra. The frequency spectra show that the signal frequencies relating to 30 and 60 times the disc speed have been removed, whilst not affecting the spectra away from these frequencies. From this point, all frequency spectra presented have been filtered in this manner.

\section{Frequency Spectra}

Frequency spectra for all 5 unsteady pressure sensors at a flow rate of $11.5 \mathrm{~g} / \mathrm{s}$ for the nominal seal clearance of $1 \mathrm{~mm}$ are shown in Figure 10. These results include a non-rotating test, in addition to the three rotation speeds tested (plotted with $\Omega=$ $8000 \mathrm{rpm}$ ), which shows very little unsteadiness. All FFT processing was conducted using a FFT window length of $4 \times 10^{4}$,
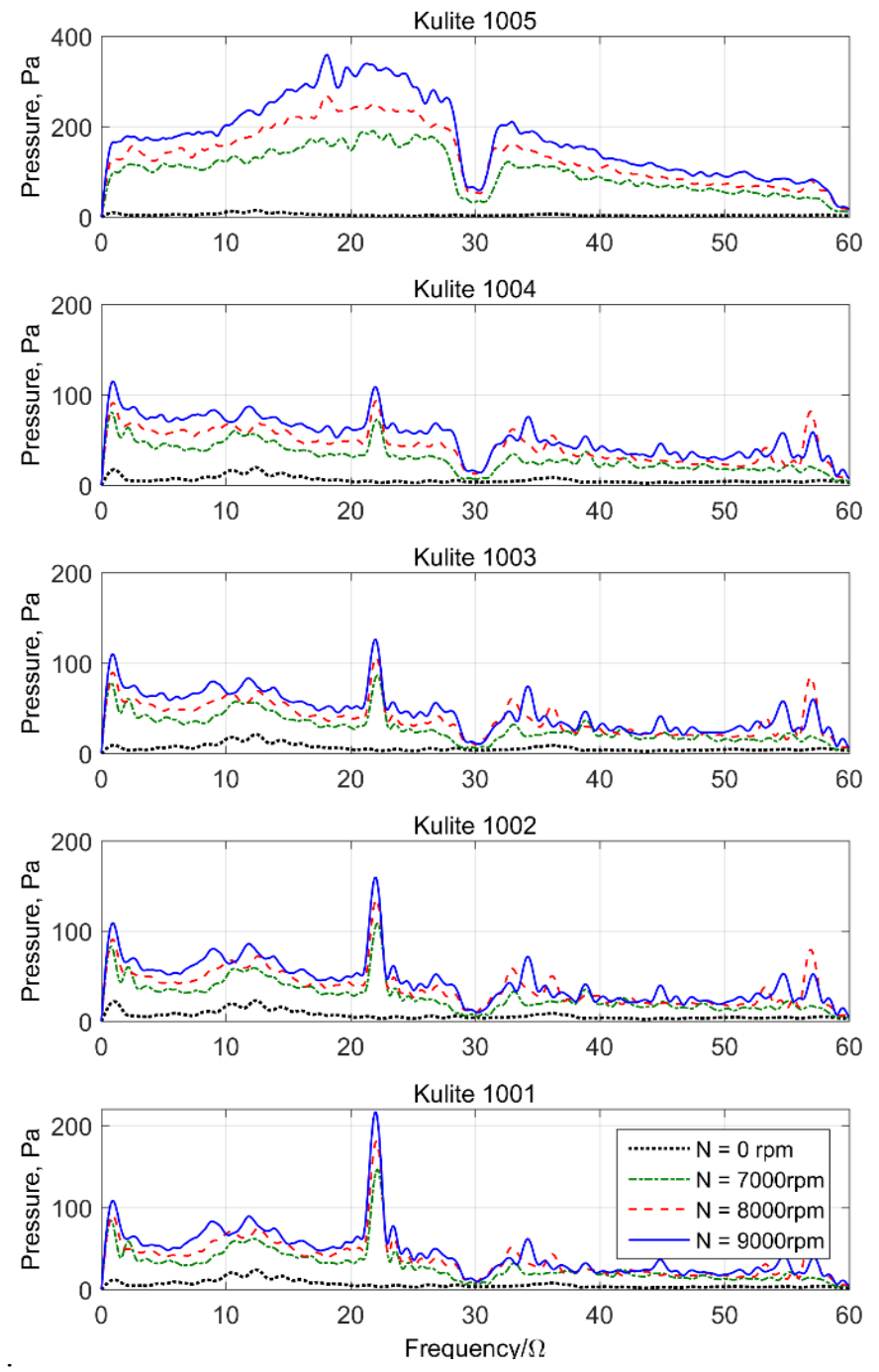

Figure 10: FFT of unsteady pressure data from radial tappings; $s_{c}=1 \mathrm{~mm}, \dot{m}=11.5 \mathrm{~g} / \mathrm{s}, \operatorname{Re}_{\emptyset}=0-3 \times 10^{6}, C_{w}=2.5 \times 10^{3}$ providing a frequency spacing of $25 \mathrm{~Hz}$ and a maximum uncertainty in a $f / \Omega$ peak location of $2.16 \times 10^{-1}$.

In the cavity, a distinct frequency peak at $\sim 22 \Omega$ is evident, which diminishes slightly with increasing radius (moving from position 1001 to 1004), but is still evident at position 1004 close to the rim seal. As the amplitude of the distinct frequency increases with decreasing radius, the origin of this excitation may be located further upstream. Note the change in scale for data at position 1005 which is in the seal gap. Here the level of unsteadiness is higher than in the cavity with a much broader spread of frequencies. An increase in the level of unsteadiness with increasing rotor speed is also more evident.

Results from the rotating tests for the $1 \mathrm{~mm}$ gap are further illustrated in Figure 11. This gives the frequency spectra for the
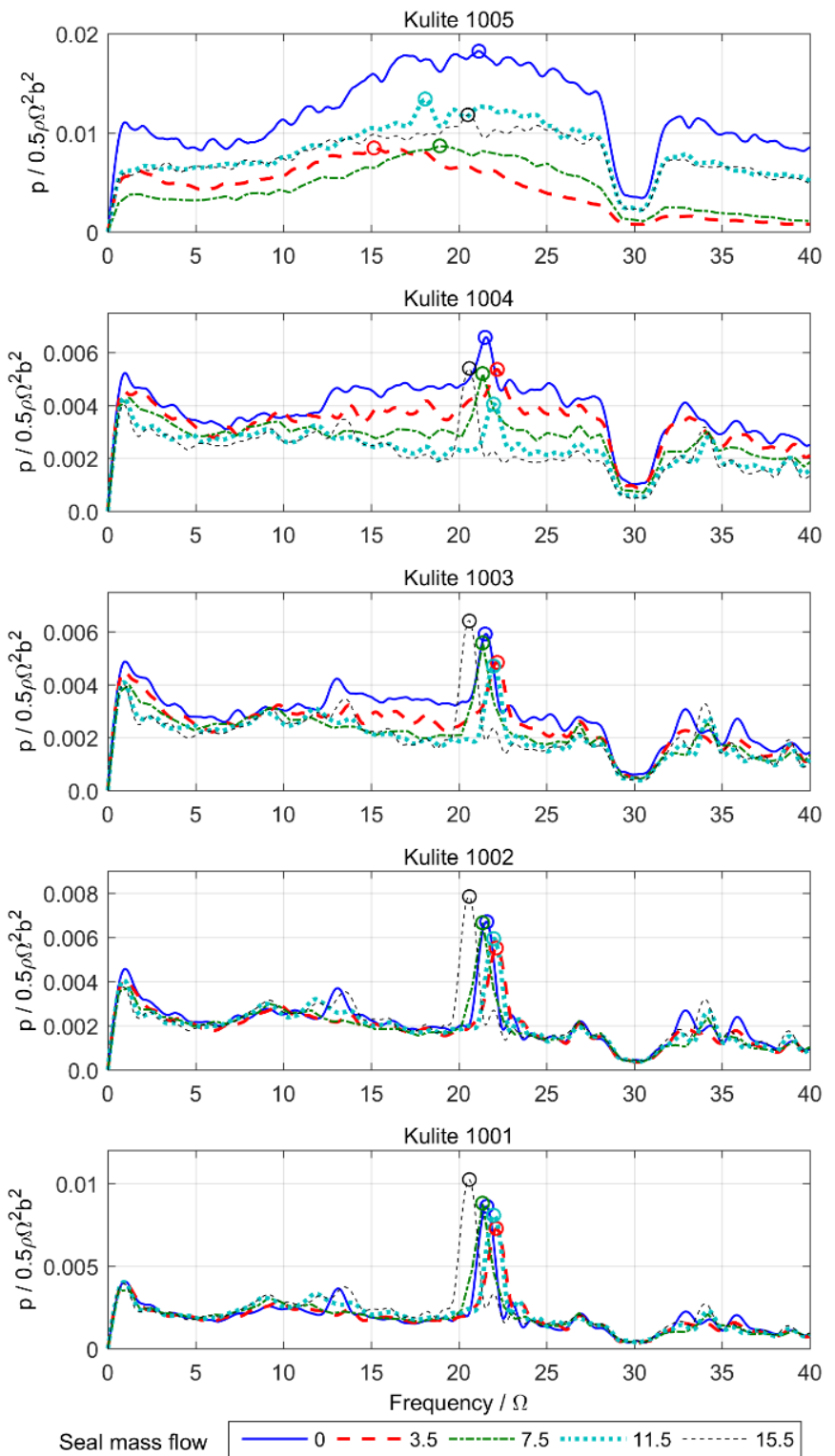

Figure 11: FFT of unsteady pressure data from radial tappings; $s_{c}=1 \mathrm{~mm}, \Omega=9000 \mathrm{rpm}, \operatorname{Re}_{\emptyset}=3 \times 10^{6}, C_{w}=0-3.4 \times 10^{3}$ (circles show peak $f / \Omega \& p / 0.5 \rho \Omega^{2} b^{2}$ plotted in subsequent figures) 
range of test flow rates at $9000 \mathrm{rpm}$. Broadly similar trends were observed at all speeds and for the $1.65 \mathrm{~mm}$ seal gap. There is a small but noticeable effect of flow rate on the frequency and amplitude of the distinct frequency in the cavity. The level of unsteadiness is most sensitive to flow rate within the seal (at position 1005), where the lowest level of unsteadiness occurs at an intermediate flow rate. Generally the spectra for the measurements within the cavity are more prone to show distinct frequencies than those within the seal.

Further trends regarding the distinct frequency at $\sim 22 \Omega$ are shown in Figure 12 and Figure 13. These show variation of the non-dimensional amplitude and frequency of this component with non-dimensional flow rate at the 5 measurement positions for all three speeds and for the two seal gaps. In these figures the lines joining the data points are for visual aid only.

It is clear that this non-dimensional form achieves a good collapse of the data acquired at the three innermost sensor locations. The results show that, within the cavity, the nondimensional peak frequency $f / \Omega$ of the dominant component is only slightly dependent on flow rate, rotational speed and seal clearance, and this is consistent with the weak dependency of
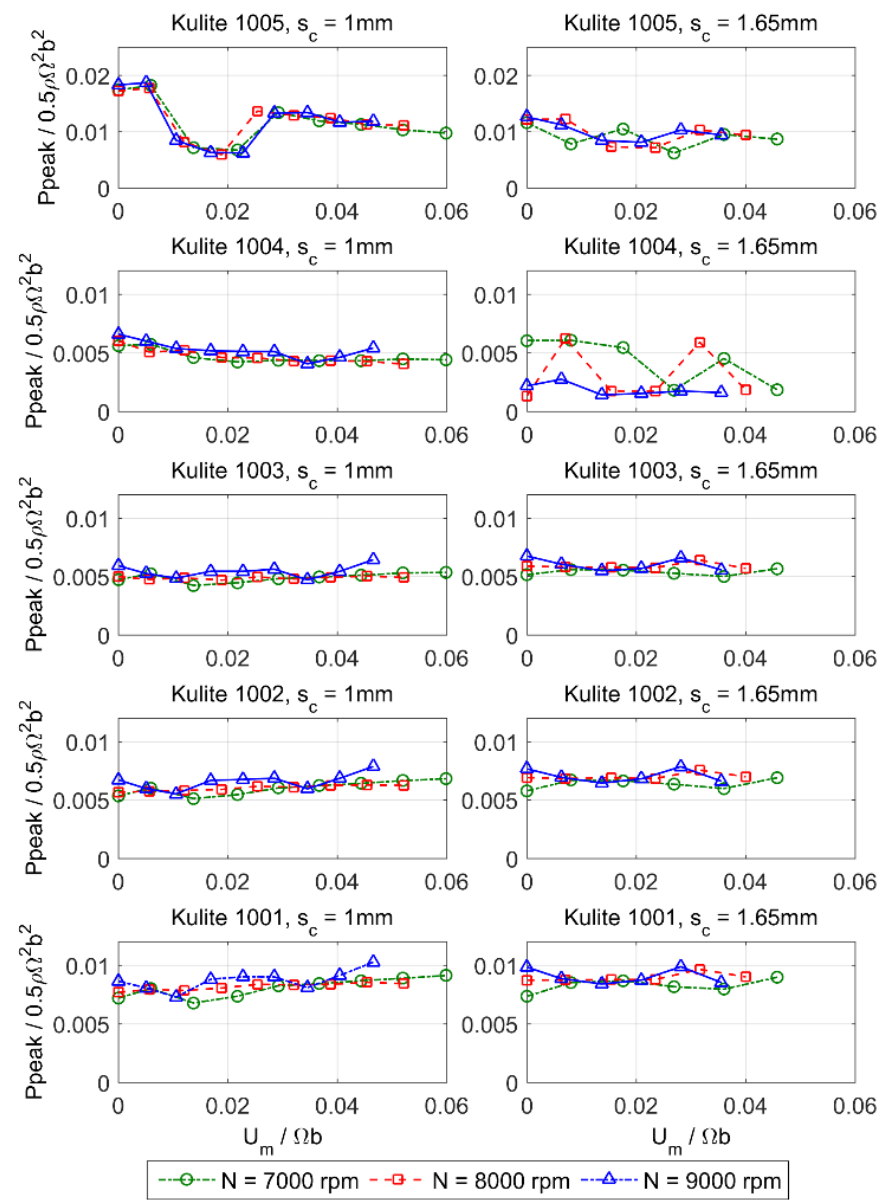

Figure 12: Comparison of $p_{\text {peak }} / 0.5 \rho \Omega^{2} b^{2}$ versus $u_{m} / \Omega b$ for all sensor locations and both seal gap sizes: $s_{c}=1 \mathrm{~mm}$ (left); $s_{c}=1.65 \mathrm{~mm}$ (right); $\operatorname{Re}_{\emptyset}=2.2-3 \times 10^{6}, C_{w}=0-3.4 \times 10^{3}$
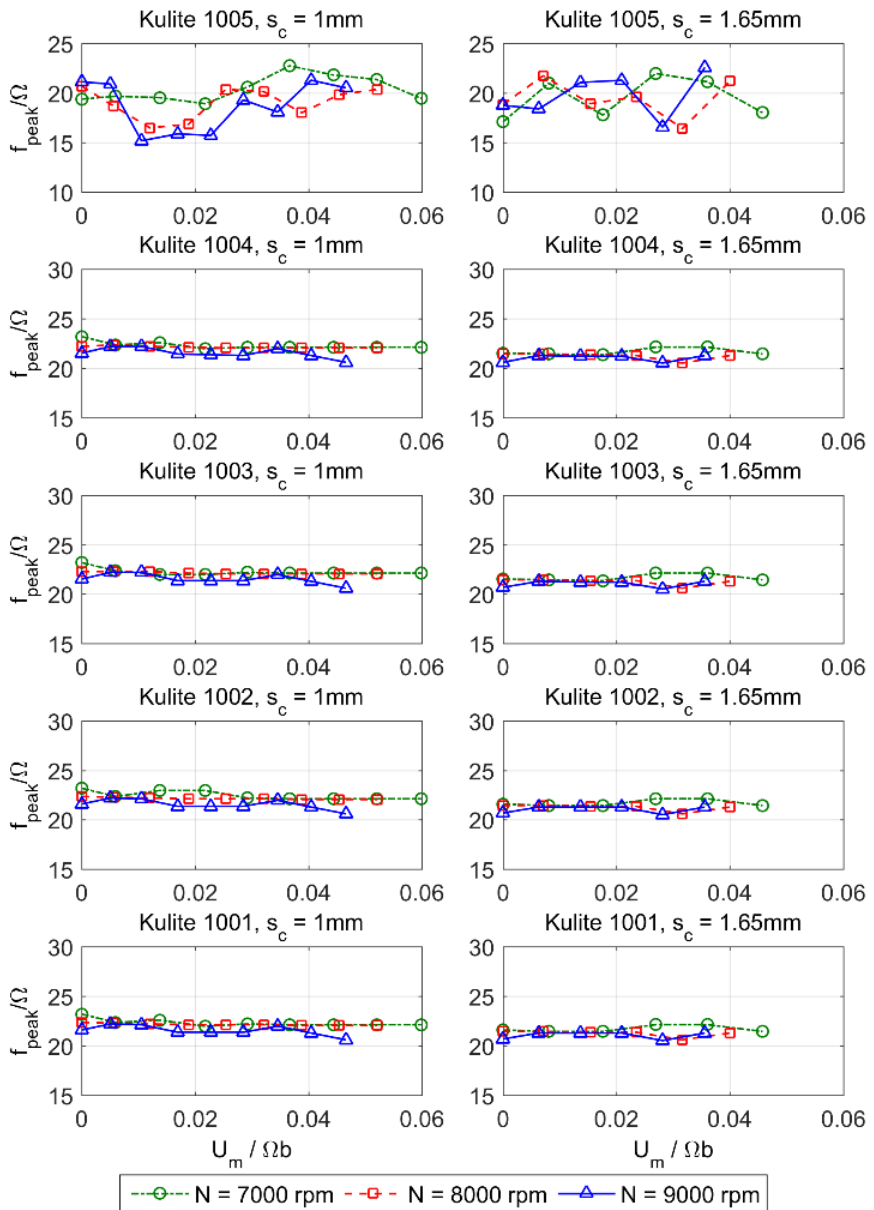

Figure 13: Comparison of peak $f / \Omega$ versus $u_{m} / \Omega b$ for all sensor locations and both seal gap sizes: $s_{c}=1 \mathrm{~mm}$ (left);

$s_{c}=1.65 \mathrm{~mm}$ (right); $\operatorname{Re}_{\emptyset}=2.2-3 \times 10^{6}, C_{w}=0-3.4 \times 10^{3}$

the mean flow in the cavity on these parameters discussed previously. The peak frequency at position 1004 also shows little variation, indicating that the distinct cavity frequency is observed at this position for all cases, although the full spectra show that it is relatively weak in some cases. Amplitudes at this position show some variation for the $1.65 \mathrm{~mm}$ clearance seal, suggesting greater influence of the flow within the seal at the higher seal clearance for this measurement position. Note also the relatively low level of unsteadiness at this location for the $1.65 \mathrm{~mm}$ gap at $9000 \mathrm{rpm}$ compared to the $1 \mathrm{~mm}$ gap results. Frequencies at sensor location 1005 show similar levels of scatter for the two clearances, resulting from the lack of a distinct frequency at this position. Amplitudes at position 1005 show different behaviour for the two clearances. For the $1 \mathrm{~mm}$ gap, the highest levels of unsteadiness occur at zero or very low flow rates and minima in levels of unsteadiness occur at values of $u_{m} / \Omega b$ in the range $\sim 0.01$ to $\sim 0.03$. This is below the value of $u_{m} / \Omega b \sim 0.033$ identified from the mean flow results as the condition at which the mean pressure level in the outer part of the cavity equals the external pressure. Thus both the maximum and minimum levels of unsteadiness occur at conditions when ingestion of external flow into the cavity is expected. 
The $1.65 \mathrm{~mm}$ gap results at position 1005 do not show the minimum around $\mathrm{u}_{\mathrm{m}} / \Omega \mathrm{b}=0.015$ observed for the tighter seal clearance. This may be an effect of the much reduced axial overlap for the larger clearance. As the larger clearance was achieved by axial movement of the vane platform ring this resulted in the seal having very little axial overlap, which changes the relative position of sensor 1005 to the seal significantly, and may account for the lower levels of unsteadiness for at this position compared to the results with a seal gap of $1 \mathrm{~mm}$.

\section{Cavity Flow Structure}

The unsteady flow structure in the rim seal cavity has been further investigated through analysis of the circumferentially distributed unsteady pressure measurements at $r / b=0.96$. In particular the phasing of the signals at different circumferential locations was examined for evidence of rotating flow structures similar to those observed in previously published unsteady CFD studies.

Figure 14 illustrates how a periodic flow structure rotating at angular velocity $\omega_{s}$ will affect a flow measurement at two stationary probes at the same radius but at circumferential positions differing by a known angle $\alpha$. If the flow structure has $N$ lobes, then the angle between each lobe is $\beta=2 \pi / N$ radians. The measurements at probes 1 and 2 will both detect the same frequency $(f)$ with a phase lag of $\Delta t_{\alpha}=\alpha / \omega_{s}$, corresponding to the time it takes for a flow feature to travel between the two probes. The angular frequency detected at each probe $f=2 \pi / \Delta t_{\beta}$, where $\Delta t_{\beta}=\beta / \omega_{s}$ is the time taken for a flow feature to travel through an angle $\beta$. These relations give four equations involving the six unknown parameters: $f, N, \beta, \omega_{s}$, $\Delta t_{\alpha}$ and $\Delta t_{\beta}$. The measured frequency $f$ and the phase difference between the signals at the two probes are required to determine the number of lobes $N$ and angular speed $\omega_{s}$ characterising the unsteady flow structure. In general, the angle between the probes $\alpha$ will not always be less than the angle $\beta$

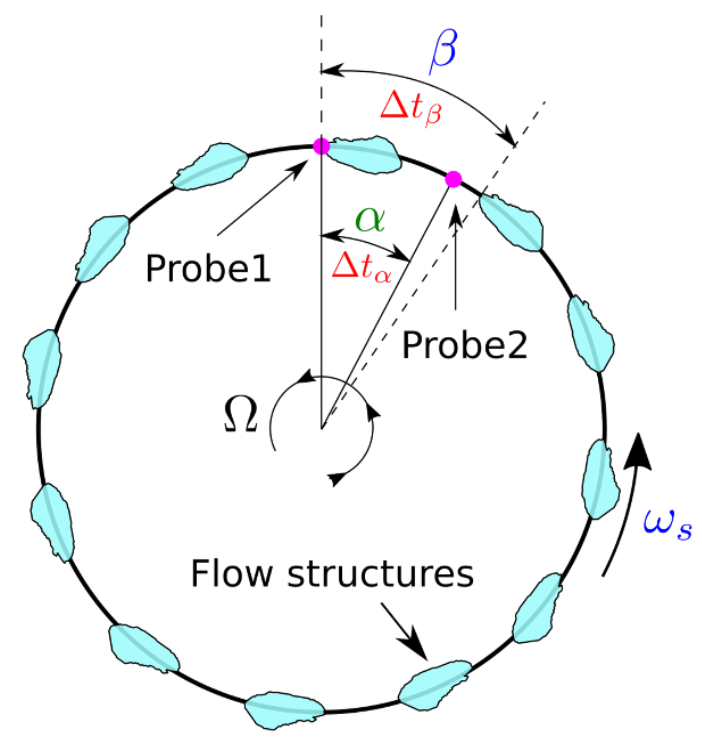

Figure 14: Illustration of cavity flow structure between flow features (as it is drawn in the Figure 14). The determination of the phase difference is further complicated as cross correlation of the two signals will show multiple results for the phase lag corresponding to the $N$ lobes, such that $\Delta t_{\alpha}=$ $\alpha / \omega_{s}+n \Delta t_{\beta}$ where $n$ is any integer.

Prior to cross correlation of the unsteady pressure data, the measurements from each probe were first filtered to remove components outside the region of interest around $f=22 \Omega$. Examples of the filtered signals from the six circumferentially distributed sensors are shown in Figure 15 for the $1 \mathrm{~mm}$ seal gap at $9000 \mathrm{rpm}$ with a flow rate of $11.5 \mathrm{~g} / \mathrm{s}$. While some lower frequency modulation is still apparent the signals all clearly show the frequency of interest with good repeatability at different circumferential positions. Examination of the spectra at this condition showed the peak frequency to be $21.36 \Omega$.

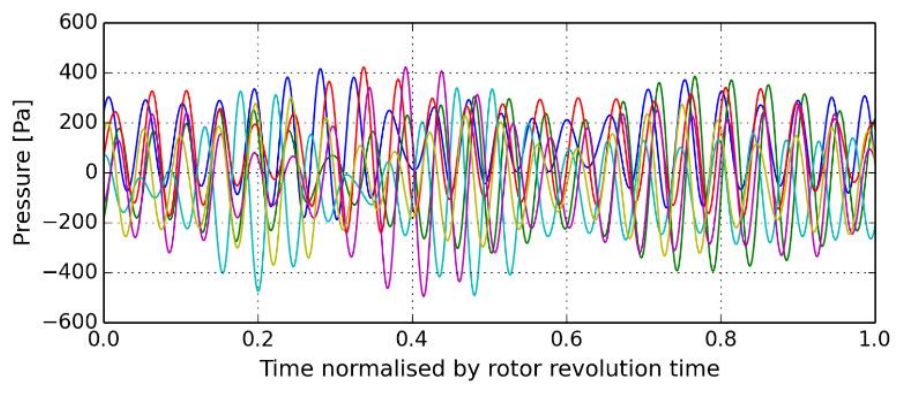

Figure 15: Filtered unsteady data for the six circumferentially spaced sensors: $s_{c}=1 \mathrm{~mm}, \dot{m}=11.5 \mathrm{~g} / \mathrm{s}$ and $\Omega=9000 \mathrm{rpm}$ $\left(\operatorname{Re}_{\emptyset}=2.9 \times 10^{6}, C_{w}=2.5 \times 10^{3}\right)$

Cross correlation of all possible pairs of the six sensors was examined. Results for sensors 1007 and 1008, with a spacing of $5^{\circ}$, are illustrated in Figure 16. This gives the correlation of the two signals obtained from analysing data over one rotor revolution. The time lag between the two signals is normalised by the period for one rotor rotation. Peaks in the correlation coefficient at equally spaced intervals are apparent, as expected for a rotating flow structure. If, for a flow structure rotating in the same direction as the rotor, the angle between flow structures $(\beta)$ is greater than the angle between the two probes $\left(\alpha=5^{\circ}\right)$ then the time interval from $0 \mathrm{~s}$ to the first peak with positive lag time is expected to correspond to the time $\Delta t_{\alpha}$ for the flow structure to rotate through angle $\alpha$. The interval between two adjacent positive peaks corresponds to the time lag between two neighboring flow structures $\Delta t_{\beta}$.

Cross correlations of the two signals were repeated for each of 150 revolutions. The results are summarised in Figure 17. This records the lag time with the peak cross correlation from each revolution. The histogram shows the number of times a peak was found in each 0.005 interval of normalised lag time. For example, in the case shown analysis from 26 of the 150 revolutions indicated strongest correlation in the band $0.01<\Delta t_{\alpha} \Omega / 2 \pi<0.02$, i.e. the first group of bars with positive lag time. The grouping of the results in uniformly spaced blocks again indicates a rotating flow structure with some circumferential periodicity. 


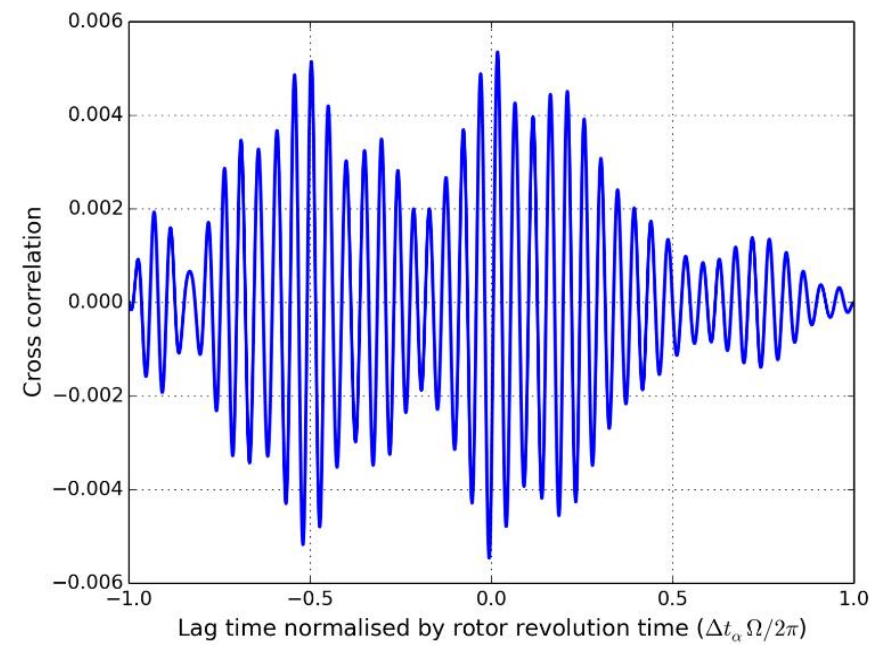

Figure 16: Results of cross correlation over one revolution of sensors 1007 and 1008: $s_{c}=1 \mathrm{~mm}, \dot{m}=11.5 \mathrm{~g} / \mathrm{s}$ and $\Omega=9000 \mathrm{rpm}$ $\left(\operatorname{Re}_{\emptyset}=2.9 \times 10^{6}, C_{w}=2.5 \times 10^{3}\right)$

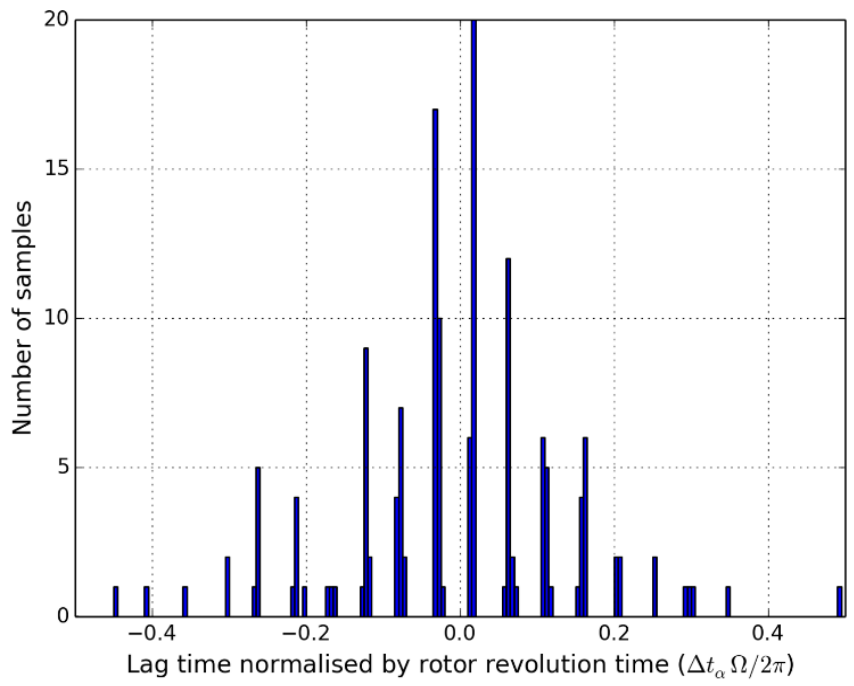

Figure 17: Histogram of normalised lag time from analysis of 150 revolutions for sensors 1007 and 1008: $s_{c}=1 \mathrm{~mm}, \dot{m}=11.5 \mathrm{~g} / \mathrm{s}$ and $\Omega=9000 \mathrm{rpm}$.

The middle plot in Figure 18 summarises results from cross correlation of all possible pairs of the six circumferentially spaced transducers. The angle between the sensor pairs $(\alpha)$ is shown on the vertical axis. The lower horizontal axis shows the normalised average time lag $\left(\Delta t_{\alpha} \Omega / 2 \pi\right)$ for results in each of the uniformly spaced groups (as illustrated in Figure 17). This phase difference can also be presented as the angle turned by the rotor in time $\Delta t_{\alpha}$, and this is shown on the top horizontal scale. The areas of the circles defining the data points are proportional to the number of samples (from the 150 revolutions) that contributed to this average value of the time lag. The data points all lie on a series of equally spaced parallel lines indicative of a rotating flow pattern with circumferential periodicity. The slope and spacing of the lines indicate a lobed structure with $N=27$ rotating at an angular velocity $\omega_{s}=0.79 \Omega$. The vertical spacing corresponds to the angle between lobes of the flow
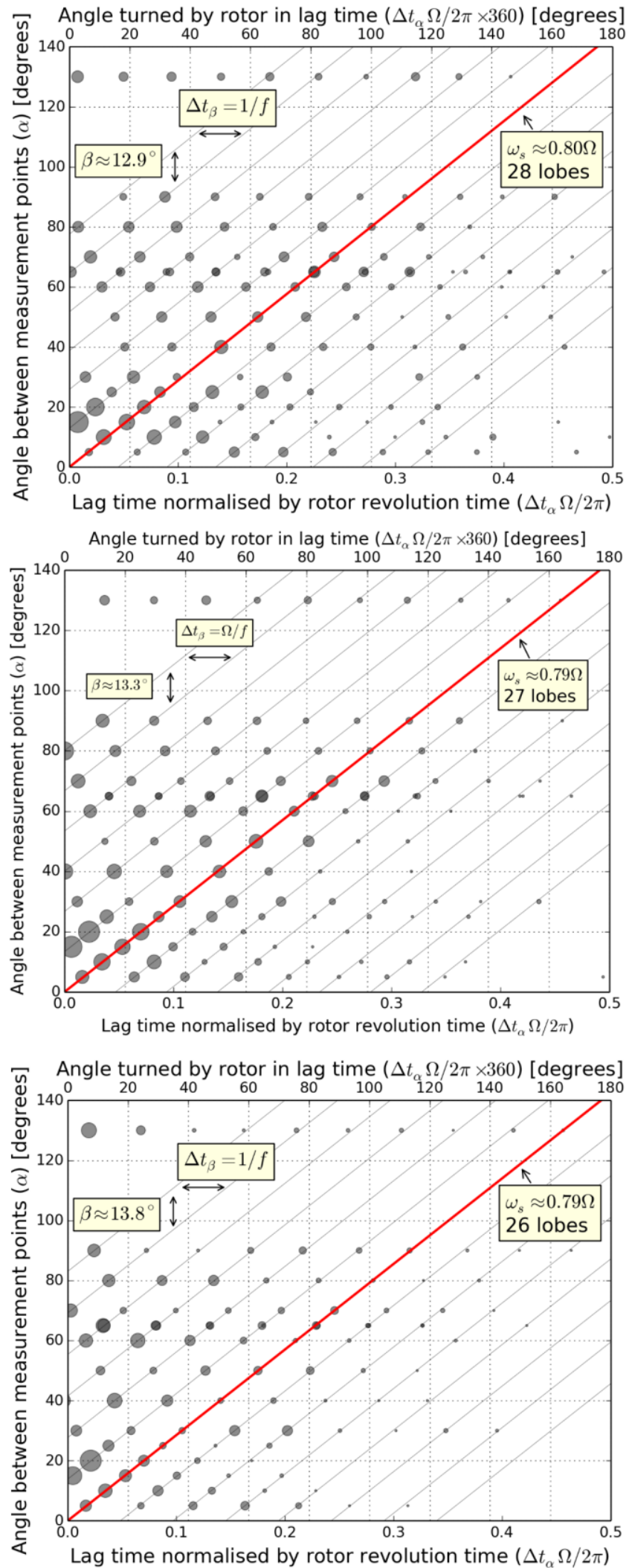

Figure 18: Summary plots for cross correlation of all sensor pairs for $s_{c}=1 \mathrm{~mm}, \Omega=9000 \mathrm{rpm}: \dot{m}=0 \mathrm{~g} / \mathrm{s}$ (bottom), $\dot{m}=11.5 \mathrm{~g} / \mathrm{s}$ (middle) and $\dot{m}=15.5 \mathrm{~g} / \mathrm{s}$ (top); $\left(\operatorname{Re}_{\emptyset}=2.7-3.0 \times 10^{6}, C_{w}=0-3.4 \times 10^{3}\right)$ 
structure $(\beta=2 \pi / N)$ and the horizontal spacing corresponds to the normalised period of fluctuations at each sensor $\Omega / f$ (= $1 / 21.36$ in this case).

Data analysis for other test conditions has confirmed the occurrence of similar flow structures associated with the transducer frequency $\sim 22 \Omega$ for all tests. Summary plots for the cross correlation of all sensor pairs for the $1 \mathrm{~mm}$ seal gap at $9000 \mathrm{rpm}$ with mass flow rates of $0 \mathrm{~g} / \mathrm{s}$ and $15.5 \mathrm{~g} / \mathrm{s}$ are shown in the bottom and top plots in Figure 18. Similar summary plots are shown in Figure 19 for the tests conducted at $7000 \mathrm{rpm}$ and mass flow rates of $0 \mathrm{~g} / \mathrm{s}, 11.5 \mathrm{~g} / \mathrm{s}$ and $15.5 \mathrm{~g} / \mathrm{s}$. Collectively these plots summarise the cavity flow structure within and at the extremes of the experimental test matrix. The number of lobes and the speed of flow structures at different rotational speeds and seal mass flow rates are summarised in Table 3. Increasing rotational speed or sealing mass flow rate reduces the number of lobes, whereas the relative speed of the flow features was found to be insensitive across the test range. Such structures are qualitatively similar to those identified in unsteady RANS solutions for chute and axial clearance seals by Boudet et al. (2005).

\begin{tabular}{|c|c|c|c|}
\hline $\begin{array}{c}\text { Rotational } \\
\text { speed }\end{array}$ & $\begin{array}{c}\text { Seal mass flow } \\
\text { rate }\end{array}$ & $\begin{array}{c}\text { Speed of flow } \\
\text { structures }\end{array}$ & $\begin{array}{c}\text { Number } \\
\text { of lobes }\end{array}$ \\
\hline \hline $7000 \mathrm{rpm}$ & $0 \mathrm{~g} / \mathrm{s}$ & $0.80 \Omega$ & 29 \\
\hline $7000 \mathrm{rpm}$ & $11.5 \mathrm{~g} / \mathrm{s}$ & $0.79 \Omega$ & 28 \\
\hline $7000 \mathrm{rpm}$ & $15.5 \mathrm{~g} / \mathrm{s}$ & $0.79 \Omega$ & 27 \\
\hline \hline $9000 \mathrm{rpm}$ & $0 \mathrm{~g} / \mathrm{s}$ & $0.80 \Omega$ & 28 \\
\hline $9000 \mathrm{rpm}$ & $11.5 \mathrm{~g} / \mathrm{s}$ & $0.79 \Omega$ & 27 \\
\hline $9000 \mathrm{rpm}$ & $15.5 \mathrm{~g} / \mathrm{s}$ & $0.79 \Omega$ & 26 \\
\hline
\end{tabular}

Table 3: Number of lobes and speed of flow structures for: $s_{c}=1 \mathrm{~mm}$, $\Omega=7000 \mathrm{rpm} \& 9000 \mathrm{rpm}$, and $\dot{m}=0 \mathrm{~g} / \mathrm{s}, 11.5 \mathrm{~g} / \mathrm{s} \& 15.5 \mathrm{~g} / \mathrm{s}$

\section{CONCLUSIONS}

The Oxford rotor facility (ORF) has been modified and instrumented for high quality unsteady flow measurement for research into turbine rim seal flows. Study of a relatively simple configuration with a chute style rim seal has provided new insight into the flow structure and an unprecedented level of unsteady flow data for use in evaluation of CFD models.

The configuration tested had a chute seal separating the outer rotating disc cavity from a quiescent annular flow with no blades or vanes in the annulus. For this case it was expected that relatively little seal flow would be required to prevent ingress of gas from the annulus into the cavity. This was confirmed by mean pressure measurements that indicated a pressure difference across the seal of zero at flow rates corresponding to nondimensional mean seal velocities $u_{m} \sim 0.033$ and 0.022 for the two seal clearances tested. For such relatively low flow rates the non-dimensional mean flow in the disc cavity was only weakly dependent on the flow rate and rotor speed, and the relationship between non-dimensional pressure difference across the seal and flow rate was approximately linear.
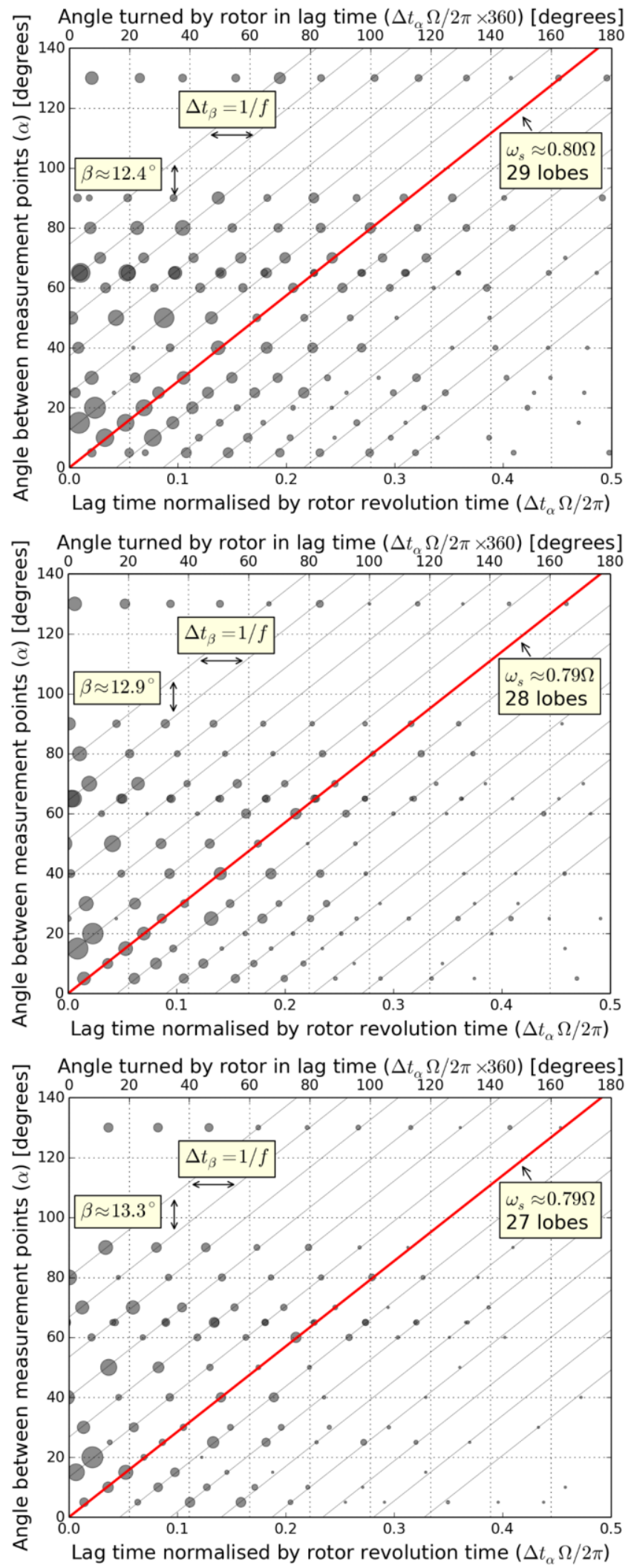

Figure 19: Summary plots for cross correlation of all sensor pairs for $s_{c}=1 \mathrm{~mm}, \Omega=7000 \mathrm{rpm}: \dot{m}=0 \mathrm{~g} / \mathrm{s}$ (bottom), $\dot{m}=11.5 \mathrm{~g} / \mathrm{s}$ (middle) and $\dot{m}=15.5 \mathrm{~g} / \mathrm{s}$ (top); $\left(\operatorname{Re}_{\emptyset}=2.2-2.5 \times 10^{6}, C_{w}=0-3.5 \times 10^{3}\right)$ 
Frequency spectra for unsteady pressure measurements in the disc cavity show a component with a distinct frequency of about 22 times the disc rotational speed. This is associated with rotating flow structures in the cavity. The distinct component in the cavity is only slightly dependent on flow rate and rotational speed. The highest levels of measured unsteadiness were within the rim seal. These were sensitive to seal flow rate and did not show such distinct peaks as for the cavity. Thus there is a clear difference between unsteadiness in the chute rim seal and the distinct component in the cavity, although there is some correspondence in frequency. The results for the $1 \mathrm{~mm}$ seal gap are broadly consistent with previous RANS and LES studies, showing relatively high levels of unsteadiness in the seal region. The similarity of the flow unsteadiness in the cavity for the two seal gaps and at all flow rates tested is remarkable. As the amplitude of the distinct frequency decreases with radius, the excitation for this may originate further upstream (inbound).

Cross correlation of circumferentially distributed pressure transducer measurements for the nominal $1 \mathrm{~mm}$ seal gap show the distinct cavity frequency is associated with large scale flow structures with 26-29 lobes rotating at about $80 \%$ of disc speed in the absolute frame of reference. This provides very clear experimental evidence of the susceptibility of disc cavity flows to such structures, confirming previously published CFD studies that showed these to be an important factor in assessing rim seal ingestion even with vanes and blades present.

The present study shows the number of lobes reducing slightly as the mass flow rate or rotor speed increase. The relative speed of the flow structures was found to be insensitive across the bounds experimental test matrix. The data obtained give direct insight into the flow in inner disc cavities and seals (unaffected by main annulus conditions). The data should also be useful in further evaluation and development of CFD methods for disc cavity and sealing flows generally.

\section{ACKNOWLEDGMENTS}

Funding for this research from Rolls-Royce plc and support from colleagues is gratefully acknowledged. In particular, we thank Matthew Miller, Peter Smout and Prof. Martin Oldfield for their contributions.

\section{REFERENCES}

[1] Chew, J.W., Hills, N.J., Hornsby, C. and Young, C., 2003. "Recent developments in application of CFD to turbomachinery internal air systems," 5th European Turbomachinery Conference (ETC5), Prague.

[2] Boudet, J., Autef, V.N.D., Chew, J.W., Hills, N.J. and Gentilhomme, O., 2005. "Numerical simulation of rim seal flows in axial turbines," The Aeronautical Journal, Vol. 109, pp. 373-383.

[3] Cao, C., Chew, J.W., Millington, P.R. and Hogg, S., 2004. "Interaction of rim seal and annulus flows in an axial flow turbine," ASME J Eng Gas Turb Pwr, Vol. 126, pp. 786-793.

[4] Boudet, J., Hills, N.J. and Chew, J., 2006. "Numerical simulation of the flow interaction between turbine main annulus and disc cavities," Proceeding of the ASME Turbo Expo 2006, Paper GT2006-90307.

[5] Gentilhomme, O., Hills, N.J., Turner, A.B. and Chew J.W., 2003. "Measurement and analysis of ingestion through a turbine rim seal," ASME J. Turbomach, Vol. 125, pp 505-512.

[6] O'Mahoney, T., Hills, N.J., Chew, J.W. and Scanlon, T., 2011. "Large Eddy Simulation of Rim Seal Ingestion," Proc. IMechE, Part C: J. Mechanical Engineering Science, Vol. 225, pp. 2881-2891.

[7] O'Mahoney, T.S.D., Hills, N.J., and Chew, J.W., 2012. "Sensitivity of LES results from turbine rim seals to changes in grid resolution and sector size," Invited paper, Progress in Aerospace Sciences, doi:10.1016/j.paerosci. 2011.09.003.

[8] Jakoby, R., Zierer, T., Lindblad, K., Larsson, J., deVito, L., Bohn, D., Funke, J., and Decker, A., 2004. Numerical simulation of the unsteady flow field in an axial gas turbine rim seal configuration. Proceedings of the ASME Turbo Expo 2004, paper GT2004-53829

[9] Zhou, D., Roy, R., Wang, C., and Glahn, J., 2009. "Main gas ingestion in a turbine stage for three rim cavity configurations, "Proceedings of the ASME Turbo Expo 2009, Paper GT2009-59851.

[10] Wang, C-Z., Mathiyalagan, S.P., Johnson, B.V., Glahn, J.A. and Cloud, D.F., 2012, "Rim seal ingestion in turbine stage from 360-dgree time-dependent numerical simulations," Proceeding of the ASME Turbo Expo 2012, Paper GT201268193.

[11] Roy, R., Feng, J., Saurabh, P., and Paolillo, R., 2004. "Experiments on gas ingestion through axial-flow turbine rim seals," Proceedings of the ASME Turbo Expo 2004, Vienna, Austria, Paper GT2004-53394.

[12] Schuepbach, P., Abhari, R.S., Rose, M.G., Germain, T., Raab, I and Gier, J., 2010. "Effects of suction and injection purge flow on the secondary flow structures of a high work turbine," ASME J. Turbomach, Vol. 132, 021021.

[13] Rabs, M., Benra, F.-K., Dohmen, H.J. and Schneider, O., 2009. "Investigation of flow instabilities near the rim cavity of a 1.5 stage gas turbine, "ASME Turbo Expo 2009, Paper GT2009-59965.

[14] Chilla, M., Hodson, H. and Newman, D., 2013. "Unsteady interaction between annulus and turbine rim seal flows," ASME J. Turbomach, Vol. 135, 051024.

[15] Ainsworth, R.W., Schultz, D.L., Davies, M.R.D., Forth, C.J.P., Hilditch, M.A., Oldfield, M.L.G., Sheard, A.G., 1988. "A transient flow facility for the study of the thermofluid-dynamics of a full stage turbine under engine representative flow conditions," ASME paper number 88-GT-144.

[16] Bayley, F.J. and Owen, J.M., 1970. "The fluid dynamics of a shrouded disc system with a radial outflow of coolant," ASME J. Gas Turb Pwr, Vol. 92, pp. 335-341.

[17] Chew, J.W., 1991. "A theoretical study of ingress for shrouded rotating disc systems with radial outflow," ASME J. Turbomach, Vol. 113, pp. 91-97. 